\title{
Numerical Investigation of Partial Blockage Effect on Film Cooling Effectiveness
}

\author{
Pan Cheng-xiong, ${ }^{1}$ Zhang Jing-zhou, ${ }^{2,3}$ and Huang Ke-nan ${ }^{1}$ \\ ${ }^{1}$ College of Energy and Power Engineering, Nanjing University of Aeronautics and Astronautics, Nanjing 210016, China \\ ${ }^{2}$ Jiangsu Province Key Laboratory of Aerospace Power System, Nanjing University of Aeronautics and Astronautics, \\ Nanjing 210016, China \\ ${ }^{3}$ Collaborative Innovation Center of Advanced Aero-Engine, Beijing 100191, China
}

Correspondence should be addressed to Zhang Jing-zhou; zhangjz@nuaa.edu.cn

Received 23 May 2014; Revised 11 July 2014; Accepted 13 July 2014; Published 27 August 2014

Academic Editor: Haochun Zhang

Copyright (C) 2014 Pan Cheng-xiong et al. This is an open access article distributed under the Creative Commons Attribution License, which permits unrestricted use, distribution, and reproduction in any medium, provided the original work is properly cited.

\begin{abstract}
Three-dimensional numerical calculation was performed to investigate the effects of partial blockage inside cylindrical film holes on the film cooling effectiveness over a flat plate. Five blockage ratios ranged from 0.1 to 0.5 and a series of blockage positions were considered under the blowing ratios of $0.3-1.5$. It is found that the blockage position has a significant influence on mainstreamcoolant jet interaction. The partial blockage located at the leading edge of coolant-hole exit mitigates the primary vortices due to mainstream-coolant jet interaction. The coolant jet penetration along vertical direction is suppressed and the peak velocity along streamwise direction is augmented under the action of partial blockage at the upstream side of film holes, providing an increment of film cooling effectiveness, especially under high blowing ratio. While the partial blockages located at the trailing or lateral edges of coolant-hole exit weaken the film cooling effectiveness. In relation to the partial blockage located in the vicinity of coolant-hole exit, the partial blockage located in the vicinity of coolant-hole inlet or middle has less impaction on the film cooling effectiveness under low blowing ratio.
\end{abstract}

\section{Introduction}

Film cooling has been employed extensively in modern gas turbine engines for cooling hot gas path components such as combustor liners and turbine blades. In the film cooling, cooling air is injected through discrete holes on the turbine component to provide a coolant film that protects the external surface from the detrimental effects of the hot combustion gases. In the real application, one of main problems of using film cooling is the imperfection inside the film cooling hole, which may affect seriously the film cooling effectiveness and heat transfer. Imperfections in the holes may result from thermal barrier coating (TBC) which can detach from the surface and results in spallation [1] and particle deposition duo to particles ingestion (such as dust, sand, fuel combustion residuals, and volcanic ash) [2]. Imperfections may also be produced during manufacturing of the holes and refurbishing of the holes after long hours of flight. It is known that imperfections in a hole may reach even $25 \%$ of hole diameter [3].

Over the past thirty years, a considerable amount of investigations have been performed in order to understand the fundamental physics involved in the film cooling and assess the knowledge on how different parameters (such as film hole shape, layout geometry, and injection angle), including surface roughness, affect the film cooling effectiveness [411]. However, limited literatures have been done with actual obstructions in and around the film cooling holes. Bunker [12] studied the effects of coolant-hole blockage on centerline adiabatic effectiveness on flat plates. The blockage was created by spraying a thermal barrier coating on the plates without protecting the film holes. The resulting coating formed a blockage inside the coolant-hole resulting in about a $30 \%$ reduction in exit area. The author noted that the coating that adhered to the inside of the coolant hole created the need for a larger pressure ratio to obtain the same flow 
rate as in the smooth case. The results also indicated a possible deflection of the coolant by the obstructions. For the round hole case, there was a $50 \%$ decrease in centerline adiabatic effectiveness immediately downstream of the hole and extending to $x / d=40$. Jovanović et al. $[13,14]$ studied the effects of coolant-hole production imperfections on film cooling performance. They found that the imperfection, placed one diameter from the hole leading edge, deteriorated the effectiveness at moderate velocity ratios. At the velocity ratio of 1.50, the exit imperfection improved the integral effectiveness relatively for more than two times. The imperfections placed deeper in the hole did not have a significant influence. Demling and Bogard [15] performed an obstruction study on the suction side of a turbine vane. It was found that there was a spatially averaged film cooling effectiveness degradation of nominally $30 \%$ for the obstruction configurations at low blowing ratios. At high blowing ratios, upstream obstructions caused 55\% adiabatic film effectiveness degradation, while the downstream obstructions had no effect. Walsh et al. [16] performed an experimental investigation directly focusing on the effects of a dust-laden coolant stream. Their study was focused on the effects of metal temperature, coolant temperature, coolant pressure ratio, number of cooling holes, sand amount, and sand diameter on coolant-hole blockage for a test coupon. Recently, Cardwell et al. [17] made an experimental investigation to evaluate sand blocking in a double wall liner whereby both impingement and filmcooling holes were simulated. Four liner geometries were tested whereby the coolant-hole size and orientation were varied in test coupons. The effects of sand flowing through a combined impingement and film-cooling double wall liner were presented.

Coolant-hole obstructions can drastically change the way the film coolant performs. Therefore, it is extremely important to know how does the discrete hole imperfection change the adiabatic film cooling effectiveness. To address this question, numerical computations have been conducted for diverse imperfections with different obstruction shapes, blocking ratios, and deposit positions. Three blowing ratios, representing low, mid, and high ratios, are studied to provide an appropriate range of data. Negative as well as positive effects of imperfections inside film cooling holes will be shown by comparison with the benchmark or perfect holes and, where possible, connected to changes in the flow structures inside the film cooling holes.

\section{Computation Scheme}

2.1. Physical Model. The baseline model for a row of cylindrical inclined holes in the flat plate is shown in Figure 1, which is corresponding to the perfected coolant-hole case. The computational domain is composed of three subzones, such as primary flow zone, perforated solid zone, and secondary flow zone. The film holes are located $19 d$ downstream of the edge of the primary passage inlet. The diameter of each hole $(d)$ is $6 \mathrm{~mm}$ and the spacing between adjacent holes is $3 d$. The holes are inclined $(\alpha) 35^{\circ}$ in the streamwise direction ( $x$-direction) with length of $3.5 d$. The length and height of
TABLE 1: Geometric dimensions corresponding to Figure 2.

\begin{tabular}{lccccc}
\hline \multicolumn{7}{c}{ Leading or trailing blockage } \\
\hline Blocking ratio $(B)$ & 0.1 & 0.2 & 0.3 & 0.4 & 0.5 \\
$a(\mathrm{~mm})$ & 3 & 4 & 4 & 4.5 & 5 \\
$\theta\left(^{\circ}\right)$ & 60 & 60 & 74 & 72 & 68 \\
\hline \multicolumn{7}{c}{ Lateral blockage } \\
\hline Blocking ratio $(B)$ & 0.1 & 0.2 & 0.3 & 0.4 & 0.5 \\
$a(\mathrm{~mm})$ & 3.3 & 4 & 4.6 & 5.2 & 5.4 \\
$\theta\left(^{\circ}\right)$ & 58 & 97 & 111 & 105 & 127 \\
\hline
\end{tabular}

primary flow passage (in $x$ - and $y$-direction, resp.) is chosen as $49 d$ and $15 d$, respectively. The width of the domain (in $z$-direction) is chosen as one spanwise hole-to-hole pitch and two symmetry plane are applied to the computational domain. The coordinate origin is located at the center of coolant-hole outlet. As the secondary flow passage is not part of this investigation, the coolant jet is simply fed into film holes from the secondary flow plenum.

The partial blockage is fixed inside the film hole, as seen in Figure 2(a). In the present study, the blockage is simply shaped as a special tetrahedron. The blockage position is determined by its azimuth-elevation of blockage orientation. For example, the blockage located at the leading edge of coolant-hole exit is marked as leading-exit. The blocking ratio adopted in the present is defined as

$$
B=\frac{4 A_{b, \text { section }} \sin \alpha}{\pi d^{2}},
$$

where $A_{b \text {,section }}$ is the cross-sectional area of blockage at the cross-sectional plane (parallel to $x$ - $z$ plane) where the apex of tetrahedron is located, as seen in Figure 2(b). In this crosssectional plane, the obstruction of the tetrahedron inside film cooling hole is the maximum.

By varying the side length $(a)$ and angle $(\theta)$, the maximum blocking ratio $(B)$ of the blockage on film hole is correspondingly changed, as seen in Table 1 .

2.2. Parameter Definition. To study the effect of various amounts of coolant flow for a fixed mainstream flow, a parameter known as the blowing ratio $(M)$ is defined:

$$
M=\frac{\left(\rho_{c} u_{c}\right)_{\text {perfect }}}{\rho_{\infty} u_{\infty}},
$$

where $\rho_{c}$ and $u_{c}$ are density and velocity of the secondary flow or coolant flow, respectively, and $\rho_{\infty}$ and $u_{\infty}$ are density and velocity of the primary flow, respectively. It is noted that the cross-sectional area of film hole with partial blockage changes from inlet to outlet; the coolant parameters defined in blowing ratio are chosen as formula (2) to ensure the same coolant mass flow under the same blowing ratio in contrast to the perfected cylindrical holes.

In order to characterize the adiabatic film cooling effectiveness $\left(\eta_{\mathrm{ad}}\right)$, the dimensionless temperature is defined as

$$
\eta_{\mathrm{ad}}=\frac{T_{\infty}-T_{\mathrm{aw}}}{T_{\infty}-T_{c}},
$$



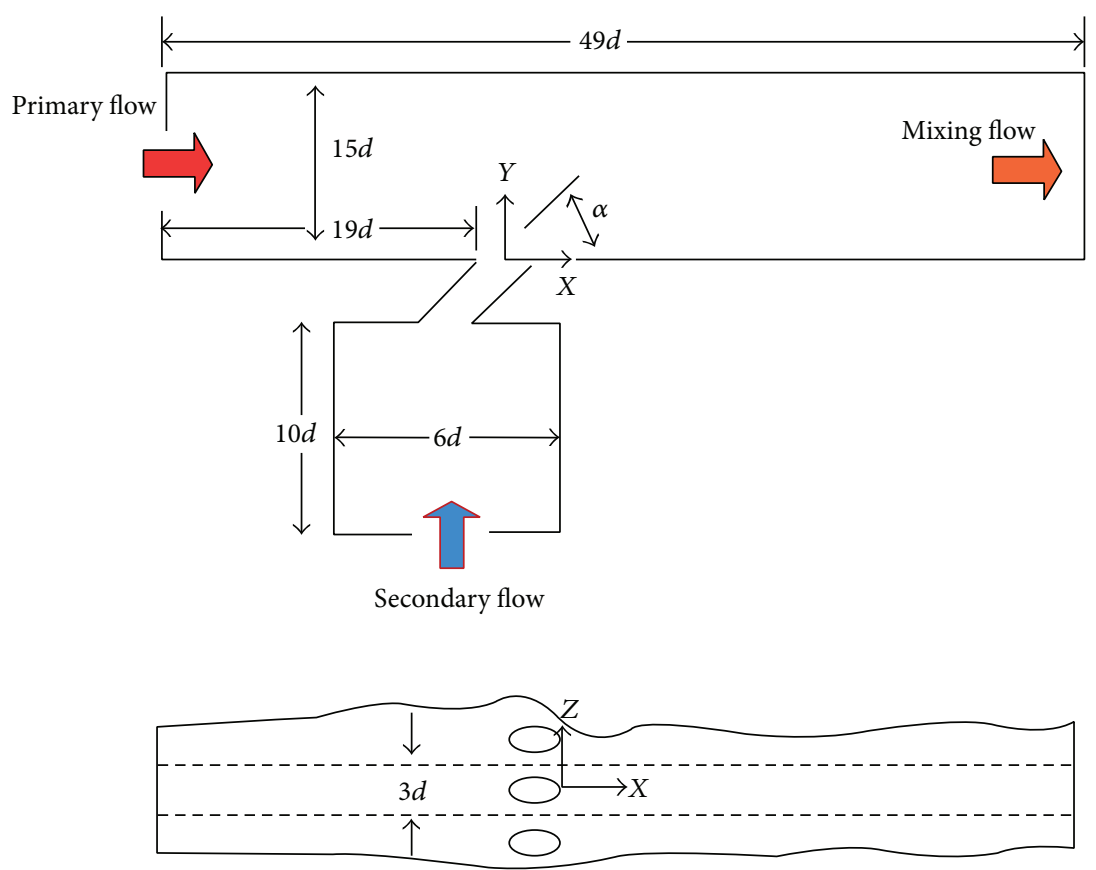

FigurE 1: Baseline case of film cooling scheme.

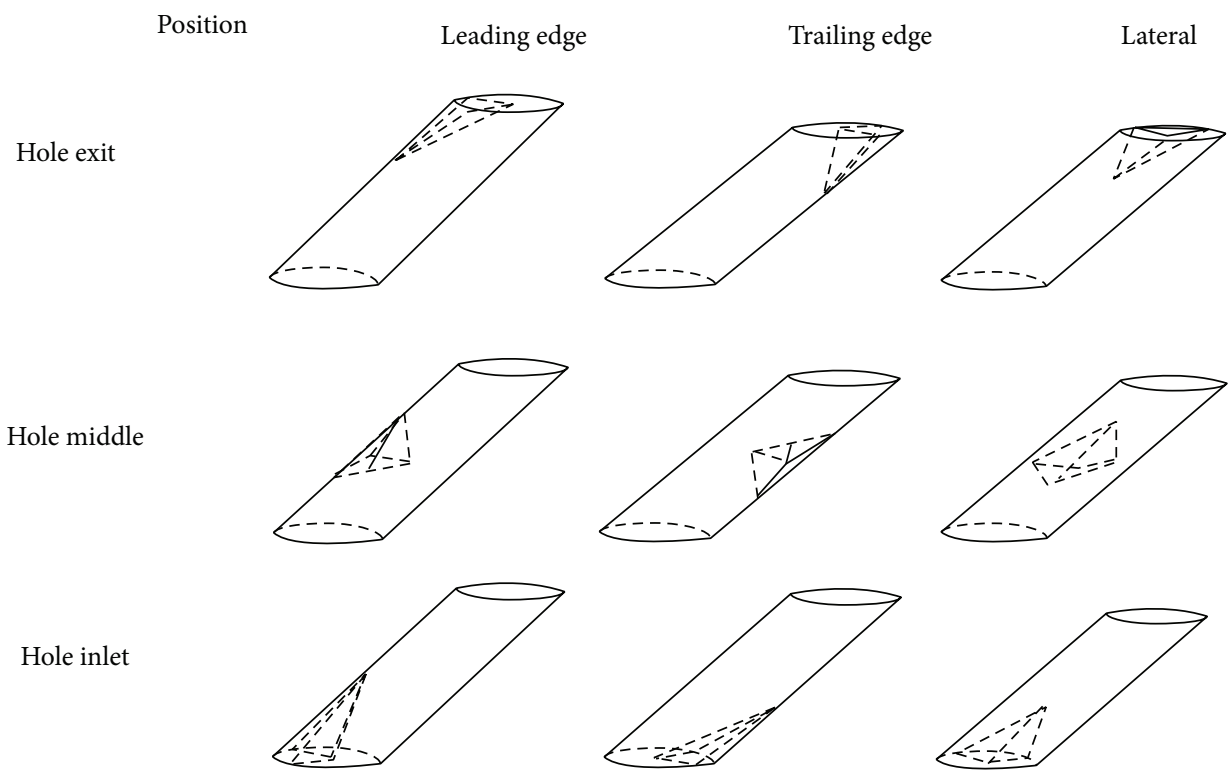

(a) Blockage position

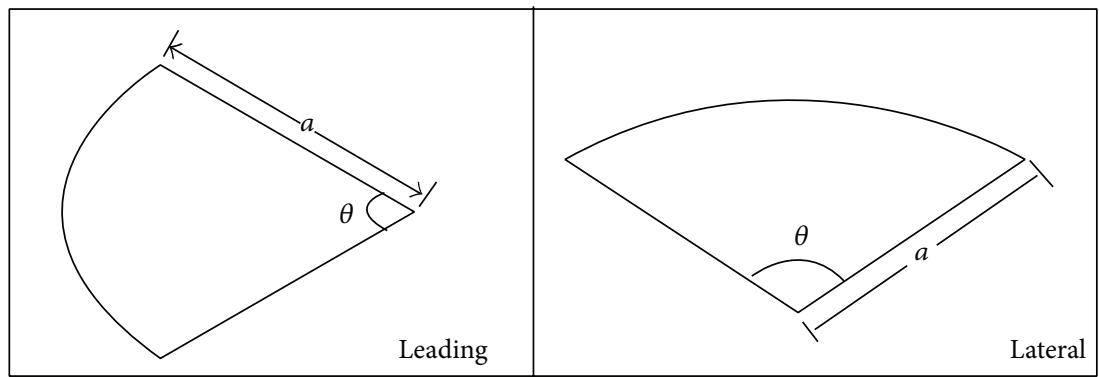

(b) Cross-sectional plane corresponding to tetrahedron apex

FIGURE 2: Schematic diagram of partial blockage inside film hole. 


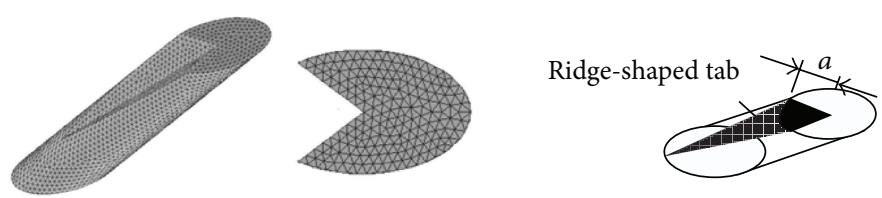

(a) Grids inside film hole

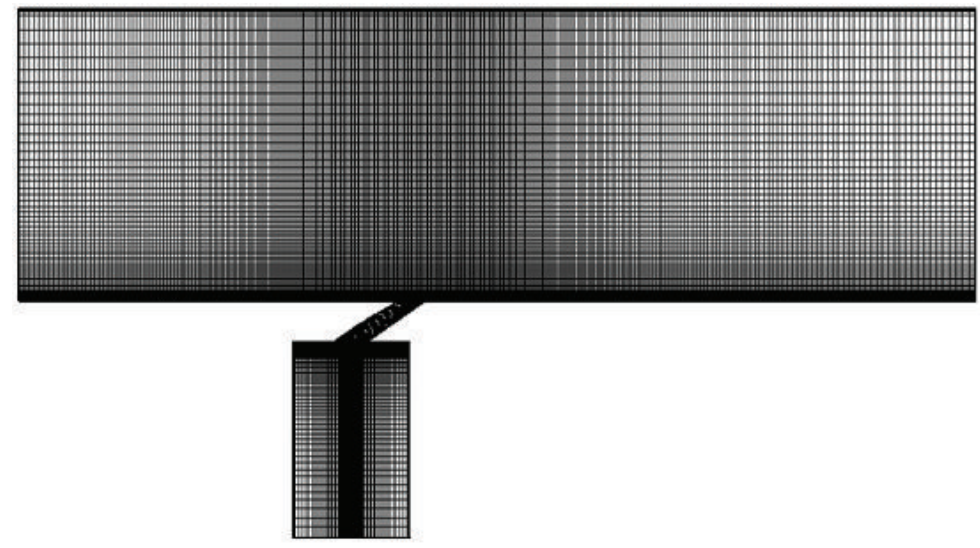

(b) Computational grids

Figure 3: Computational meshes.

where $T_{c}$ is coolant flow temperature; $T_{\infty}$ is primary flow temperature; $T_{\mathrm{aw}}$ is adiabatic wall temperature at the plate surface suffering the primary flow.

\subsection{Computational Procedure and Validation}

2.3.1. Boundary Conditions. The boundary conditions of computational domain are specified as the following.

The Primary Flow Passage. The primary flow inlet is defined as velocity-inlet with $u_{\infty}=20 \mathrm{~m} / \mathrm{s}$, and inlet temperature of the primary flow $T_{\infty}$ is $475 \mathrm{~K}$. A turbulence intensity of $0.5 \%$ and a turbulence length scale of $3 \%$ of the inlet height are used. And flow outlet condition is set as pressure-outlet with static pressure $p_{\text {out }}=101325 \mathrm{~Pa}$. No-slip condition is applied to the solid wall.

The Secondary Flow Plenum. The coolant jet is simply fed into film holes from the secondary flow cavity by adopting velocity-inlet. The temperature of secondary flow $T_{c}$ is set as $300 \mathrm{~K}$ and the inlet velocity of secondary flow is calculated according to the blowing ratio ranged from 0.3 to 1.5 .

Perforated Plate. Adiabatic no-slip condition is applied for the solid wall boundaries except for the interface between the primary flow and perforated plate. In the present study, the conductivity of the perforated plate is set as $0.01 \mathrm{~W} /(\mathrm{m} \cdot \mathrm{K})$, so that the contributions of conduction and internal cooling inside the solid wall to the film cooling effectiveness could be negligible.

Symmetry Planes. The symmetry planes are assumed to be adiabatic modeled with zero heat flux. The plane is given zero velocity in the $z$ direction thus preventing the flow from crossing the boundary but yet allowing a velocity profile to develop.

2.3.2. Computational Grids. The primary flow zone and secondary plenum are modeled with a structured mesh, and film-holes flow zone is modeled using an unstructured mesh. These two meshes are merged together to form a "hybrid" mesh, as seen in Figure 3. The meshes are nonuniform with fine grids in the regions where the complicated flow occurs, especially near the viscous walls. Viscous clustering was employed at all solid walls with a $y^{+}$value less than 2.5 at all locations. And the grid is stretched away from the viscous wall using a stretching ratio less than 1.2. By grid dependency tests, approximately 390000 computational grids are involved in the whole computational domain.

2.3.3. Computational Method. Three-dimensional numerical simulation is employed by using Fluent-CFD software. Realizable $k-\varepsilon$ turbulence model provided in the software is used to model turbulence, and the near wall region is modeled using enhanced wall functions. This turbulence model has been successfully used by some authors [18-20]. Unlike the standard $k-\varepsilon$ turbulence model, the realizable model is designed with the intent of offering viable solutions for jet-incrossflow interaction by modifying the dissipation rate and eddy-viscosity equations. The work of Harrison and Bogard has shown that this model offers fairly good predictions of film cooling performance for a two-equation model [21]. The diffusive fluxes are approximated using second-order central differences. Convergence is achieved when both of the following criteria have been met: (a) reduction in all residuals of five orders of magnitude, and (b) no observable change in local temperature prediction on the blade suction surface for additional 30 iterations. 
2.4. Computational Validation. To validate the numerical method, an example of film coolingon the plate from a row of holes with ridge-shaped tabs is illustrated. The computational model is specified according to experimental model configuration presented by Yang and Zhang [22]. Each side length ( $a$ ) of the triangular top planes is set as $4 \mathrm{~mm}$ and the correspondingly covering ratio $(B)$ of the ridge-shaped tab on film hole is about 0.21 . Figure 3 shows the computational meshes. Figure 4 compares the laterally averaged adiabatic film cooling effectiveness in terms of the experimental data and the present computational results. As observed from Figure 4, the calculated laterally averaged adiabatic film cooling effectiveness agrees well with the experimental results for the tab case; however the calculated value for the perfect hole is somewhat underpredicted. Although the relative discrepancy for the latter case is about $20 \%$, the absolute difference between the computed and measured values is only about 0.03 except for the zone tightly closed to the film hole outlet.

\section{Results and Discussion}

3.1. Effects of Blockage Position. Figure 5 presents the effects of blockage on coolant jet flow feature. In this figure, the blocking ratio and blowing ratio are fixed as 0.3 and 0.5 , respectively, and the blockage is deposited in the vicinity of coolant-hole exit. By comparison with the benchmark or perfect film holes, it is found that the film-hole obstructions significantly change the way the film coolant flows. In spite of the blockage deposition position, the coolant flow will accelerate from inlet to exit when the blockage is deposited in the vicinity of coolant-hole exit due to the decrease of crosssectional area of film hole along coolant-jet flow direction. It is also noted that the coolant flow distortion inside the film hole is tightly associated with the blockage deposition position. The leading-exit blockage makes the coolant jet turn downward, transferring the momentum of coolant-jet mainly along streamwise direction and suppressing the lift of coolant-jet to the wall, as seen in Figure 5(b), while the trailing-exit blockage makes the coolant jet turn upward, transferring more momentum of coolant-jet along normal direction, as seen in Figure 5(c). As regards to the lateral-exit blockage, the coolant-jet is forced to turn in lateral direction, as seen in Figure 5(d).

Figure 6 shows the effects of blockage on coolant-jet velocity distributions at coolant-hole exit. As the coolant is discharged from perfect hole with an inclined angle, the coolant flow velocity components from cylindrical hole can be mainly divided into two parts: the tangent velocity (in $x$-direction) and normal velocity (in $y$-direction). Although the blowing ratios for these cases are the same, the partial blockages located at trailing-exit and lateral-exit do not result in greater $x$-velocity along streamwise direction, but the significant increase of $y$-velocity. It means that the coolant jet penetration normally to the primary flow is amplified by these blockages. Viewed from the mechanism on film cooling, the blockage located at trailing-exit or lateral-exit is likely to weaken film cooling effectiveness, while, for leading-exit blockage case, the coolant-jet flow velocity along

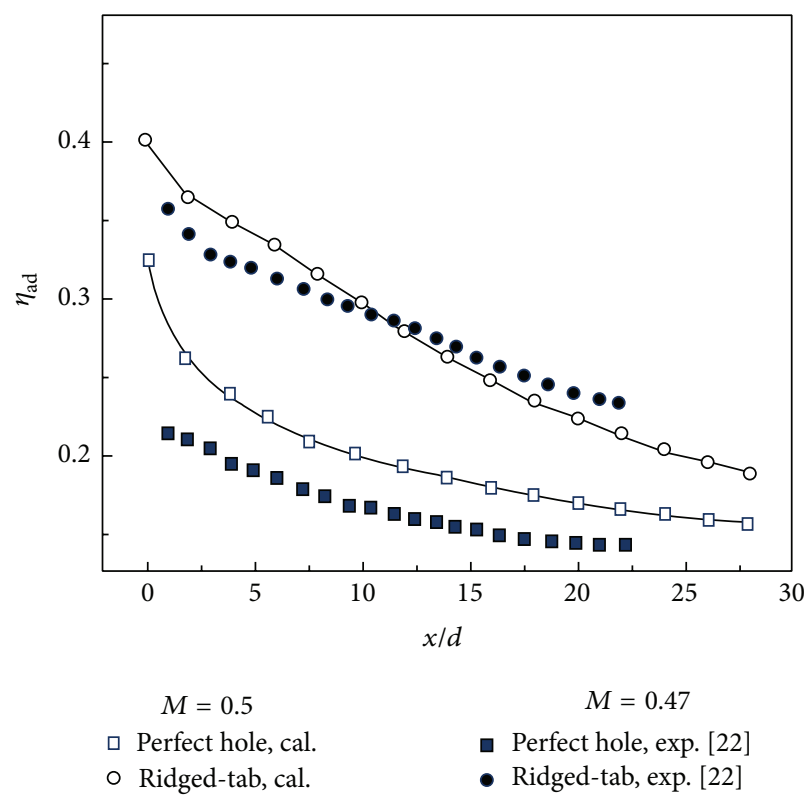

Figure 4: Comparison of computed and experimental results.

$x$-direction is augmented significantly. It is indicated that the higher coolant-jet momentum will be transferred to $x$ directional flow in this case, which is expected to maintain film-jet to flow further over the surface of the film plate and likely to lead to enhancement of film cooling effectiveness.

Figure 7 presents the effects of blockage on secondary flow vectors and isotherm contours at the streamwise planes of $x / d=1$ for a representative blowing ratio of 0.5 and blocking ratio of 0.3 . It is known that the interaction between coolant jet from discrete film holes and the mainstream flow results in the formation of kidney vortices. These vortices are detrimental to film cooling because they bring about two undesirable effects. Firstly, the hot mainstream air is forced to enter beneath the coolant jet, thus heating the plate wall. Secondly, the mutual interaction between the vortex pair tends to lift the coolant jet off the plate surface which diminishes the film cooling. By comparison with the baseline case (perfect hole), it is interesting to find that the kidney vortices are lowered obviously when the partial blockage is deposited at leading-exit, as seen in Figure 7(a). In the case of blockage deposition at leading-exit, although the local blocking also results in the increase of normal velocity at coolant-hole exit, the coolant penetration in $y$-direction at downstream of the film-hole could be efficiently suppressed by the strong coolant-jet momentum along $x$-direction. When the blockage is located at trailing-exit, the coolant-jet momentum is transferred mainly along $y$-direction, resulting in strong normal coolant-jet penetration and large scale of kidney vortices, as seen in Figure 7(b). When the blockage is located at lateral-exit, a pair of counter rotating vortices is distorted, and the scale of vortices is tended to be enlarged, as seen in Figure 7(c). As regards to the blockage deposition at lateral-middle, coolant flow inside the film-hole experiences a buffer process after the inner blockage to reach the exit. It seems that the blockage deposition at lateral-middle has 


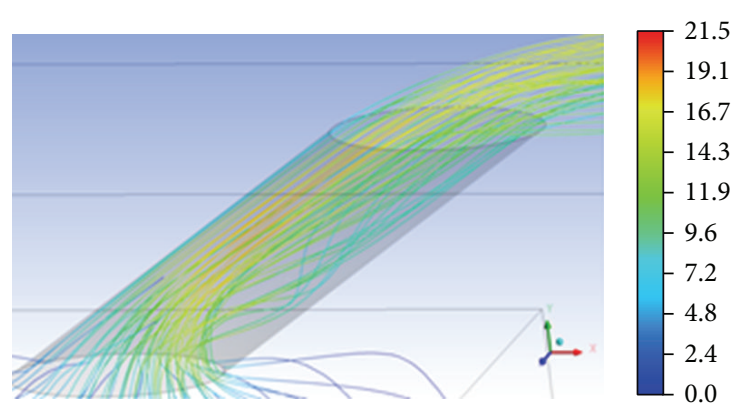

(a) Perfect

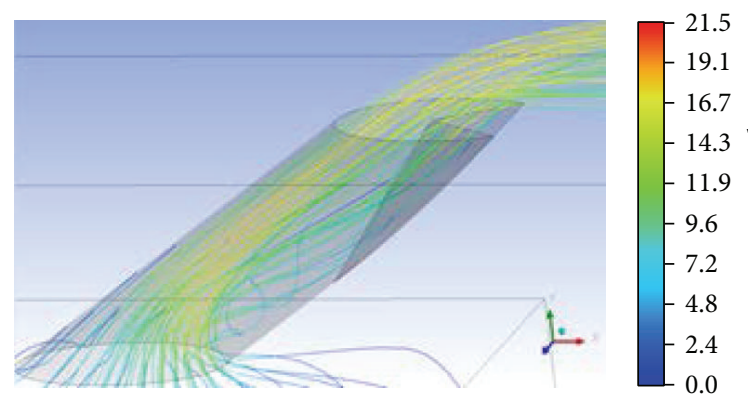

(c) Trailing-exit

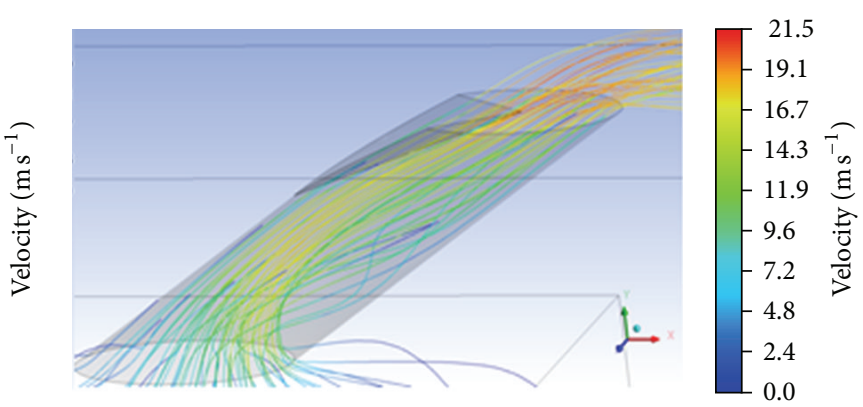

(b) Leading-exit

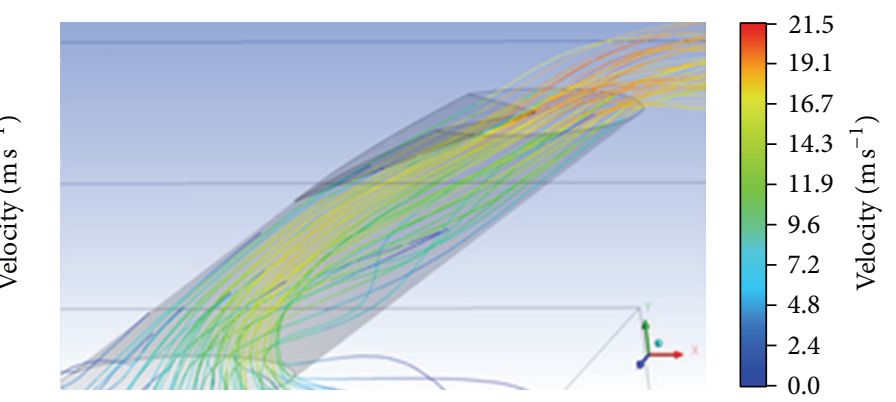

(d) Lateral-exit

Figure 5: Effects of blockage on coolant jet flow $(B=0.3, M=0.5)$.

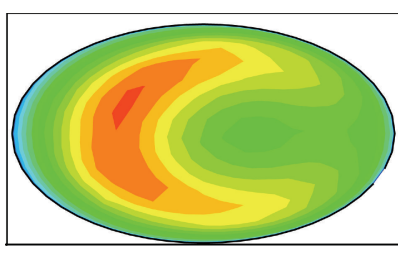

(A) Perfect

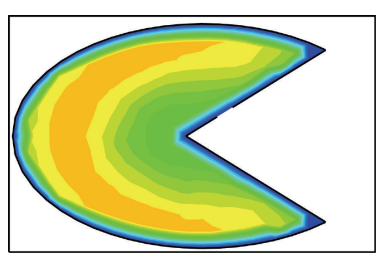

(C) Trailing-exit

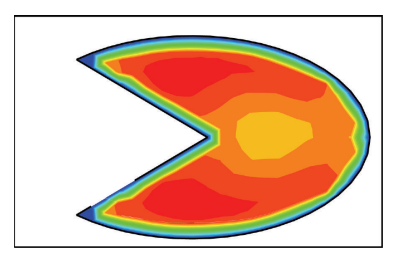

(B) Leading-exit

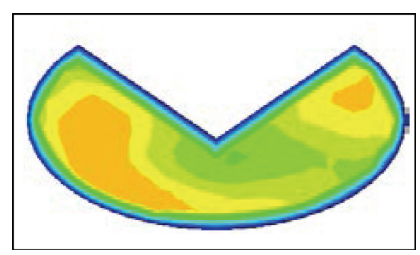

(D) Lateral-exit

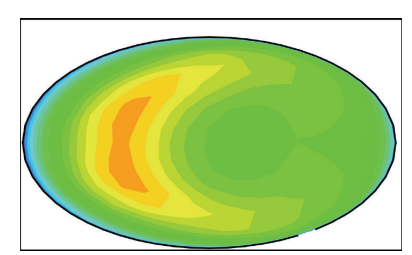

(A) Perfect

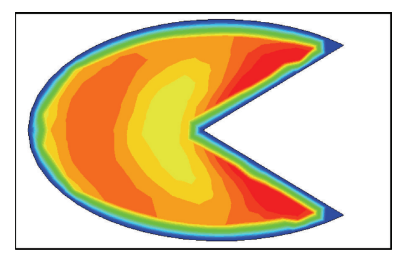

(C) Trailing-exit

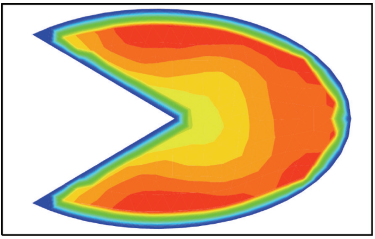

(B) Leading-exit

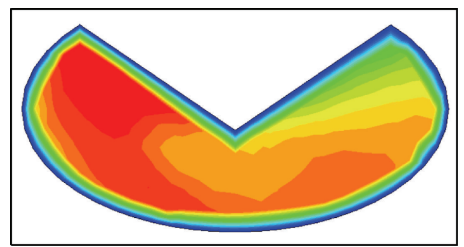

(D) Lateral-exit

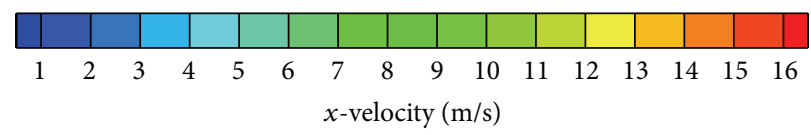

(a) $x$-velocity distributions

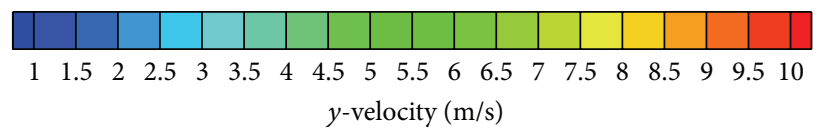

(b) $y$-velocity distributions

FIGURE 6: Effects of blockage on coolant-jet velocity distributions at coolant-hole exit $(B=0.3, M=0.5)$.

less influence on the coolant-jet penetration in relation to the lateral-exit case.

Figure 8 presents the effects of blockage on local adiabatic film cooling effectiveness distributions for a representative blowing ratio of 0.5 and blocking ratio of 0.3 . For the perfect hole, the local adiabatic film cooling effectiveness is higher or the adiabatic temperature is lower along the coolant jet centerlines, with almost no film cooling between the holes for most of the plate length. Under low blowing ratio, the coolant jet penetration to the primary flow is normally weak; the phenomenon of coolant jet lift off and reattach the surface does not appear. In relation to the baseline case, local blockage at leading-exit shows much higher film cooling effectiveness over entire region. While for the local blockage at trailing-exit 


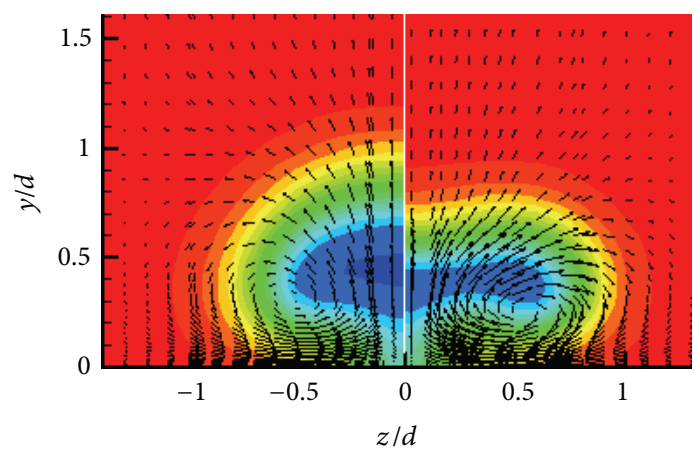

Perfect

(a)

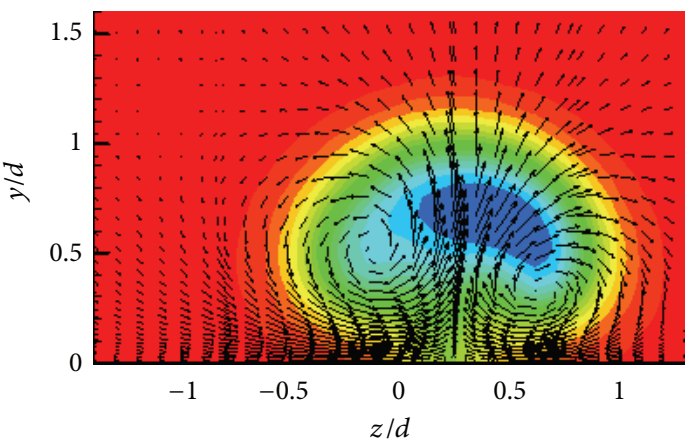

Lateral-exit

(c)

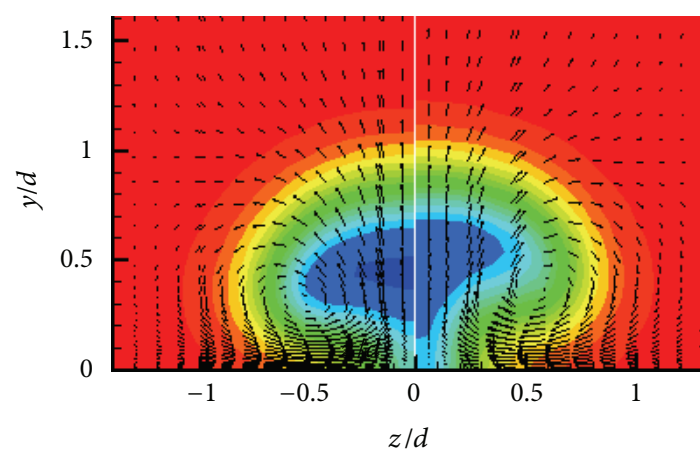

Perfect

(b)

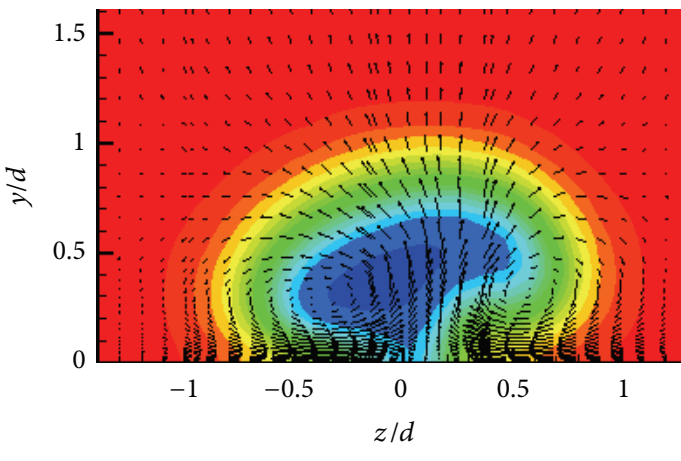

Lateral-mid

(d)

FIGURE 7: Effects of blockage on flow fields at normal plane of $x / d=1$ with blocking ratio of $0.3(M=0.5)$.

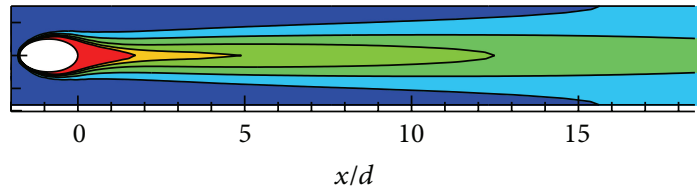

(a) Perfect
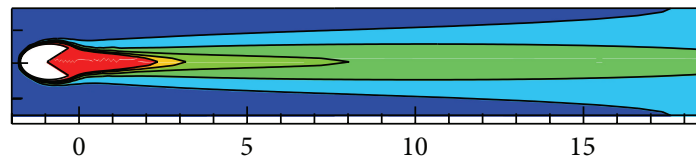

5

$x / d$

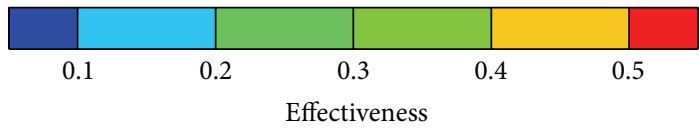

(c) Trailing-exit

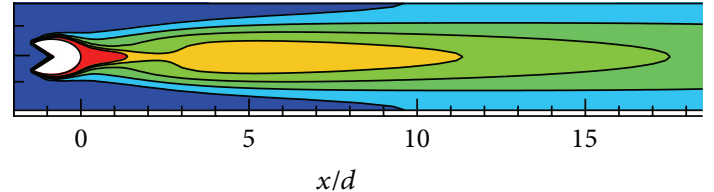

(b) Leading-exit
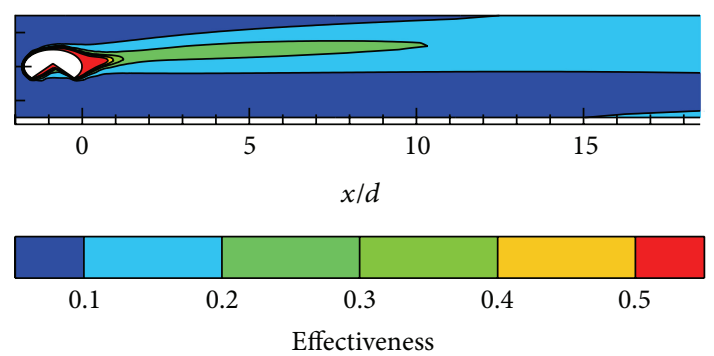

(d) Lateral-exit

FIGURE 8: Effects of blockage on local adiabatic film cooling effectiveness distributions $(M=0.5, B=0.3)$.

or lateral-exit, the coolant jet penetration to the primary flow is normally enhanced by the blockage and the jet momentum will be transferred mainly to normal direction, which is likely to lead to decrease of film cooling effectiveness. The coolantjet will be pressed by the lateral-exit blockage to flow towards one side of primary passage, resulting in the deflection of one side of film cooling effectiveness distributions.
Figure 9 presents the effects of blockage position on laterally averaged adiabatic film cooling effectiveness under blowing ratio of 0.5 and blocking ratio of 0.3 . From this figure, it is viewed that the blockage position has important influence on the film cooling characteristics. When the blockage is deposited in the vicinity of coolant-hole exit, as seen in Figure 9(a), the film cooling effectiveness is affected seriously 


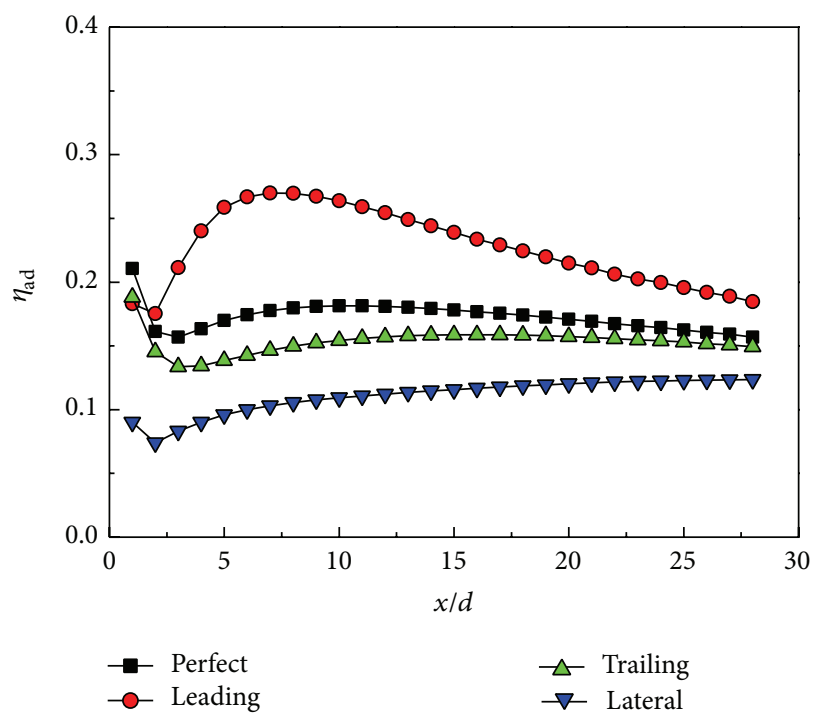

(a) Exit blockage

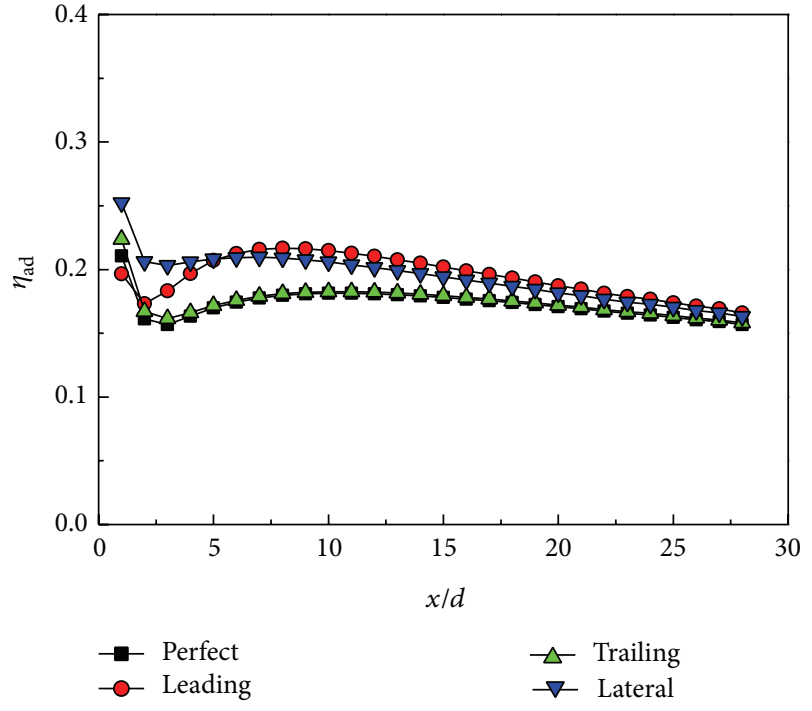

(b) Mid blockage

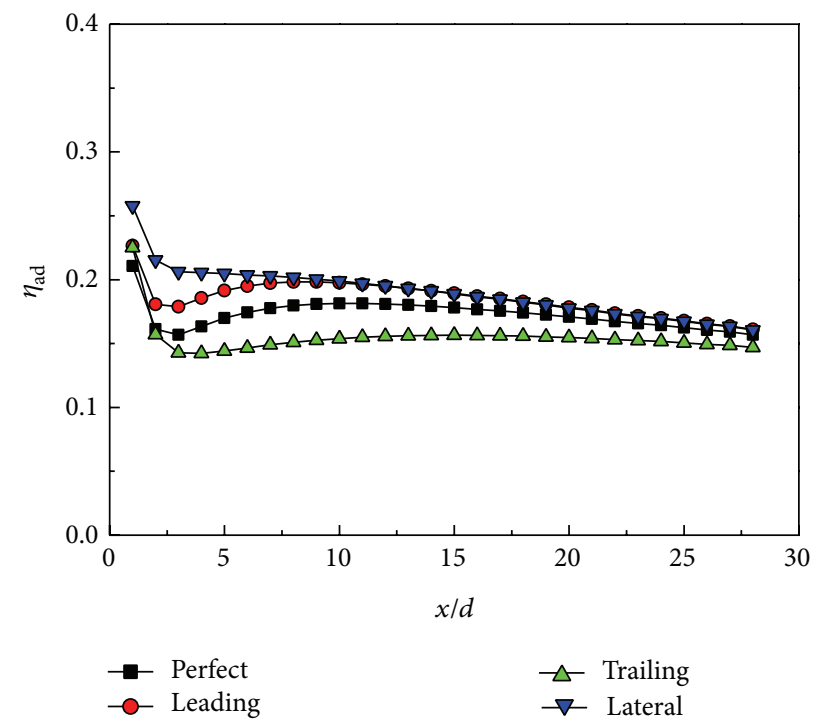

(c) Inlet blockage

FIGURE 9: Effect of blockage position on laterally-averaged adiabatic effectiveness $(M=0.5, B=0.3)$.

by the blockage. Local blockage at leading-exit shows much higher film cooling effectiveness than the baseline case, while the local blockage at trailing-exit or lateral-exit decreases the film cooling effectiveness obviously. When the blockage is deposited in the vicinity of coolant-hole inlet or middle region, as seen in Figures 9(b) and 9(c), the film cooling effectiveness is weakly affected by the blockage. As mentioned above, when the blockage deposition in the vicinity of coolant-hole inlet or middle region, coolant flow inside the film-hole experiences a buffer process after the inner blockage to reach the exit. The action of blockage on changing the coolant-jet flow velocity components either in streamwise direction or in normal direction will be weakened. Thus the enhancement of film cooling by the leading-mid or leadinginlet blockage is weakened relatively to the leading-exit case. It is also interesting that the blockage deposited at lateral-edge in the vicinity of coolant-hole inlet or middle region may result in a little higher film cooling effectiveness than the perfect hole. This blockage position may distort the coolant flow inside film-hole but does not influence the coolant flow downstream far away the blockage. In general, the blockage deposition at the trailing edge of coolant-hole seems to be the most detrimental to film cooling.

3.2. Effects of Blocking Ratio. Figure 10 presents the effects of blockage on secondary flow vectors and isotherm contours at the streamwise planes of $x / d=1$ for a representative blowing ratio of 0.5 and blocking ratio of 0.5 . By comparison with the blocking ratio of 0.3 (as seen in Figure 7), the blockage has greater influence on the coolant-jet flow as the blocking ratio increases. The blockage deposited at leading-exit with bigger blocking ratio shows more intensity on suppressing the scale 


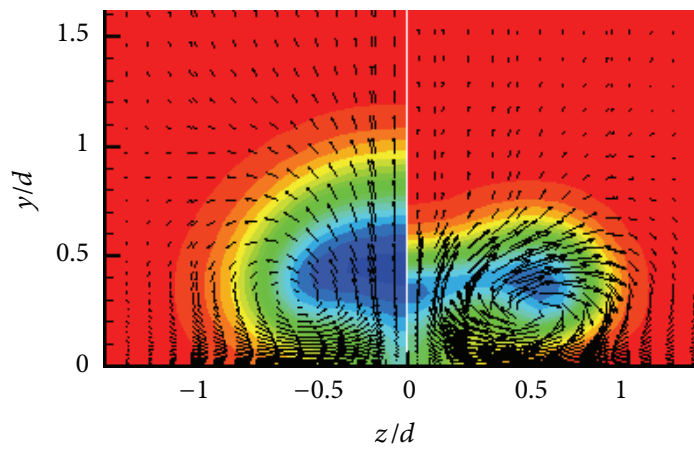

Perfect

(a)

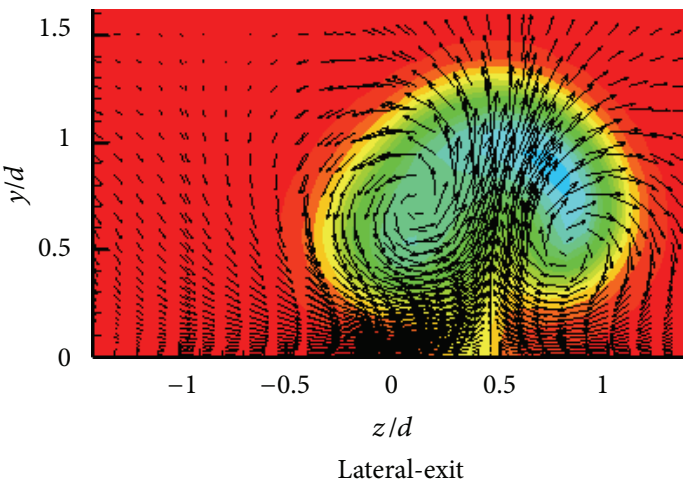

(c)

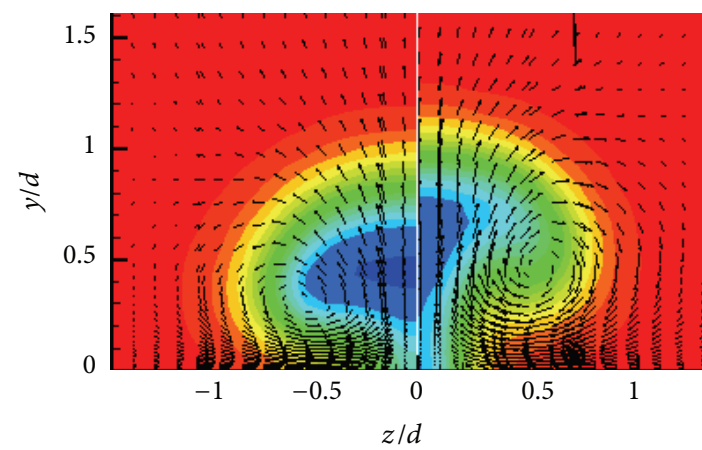

Perfect

(b)

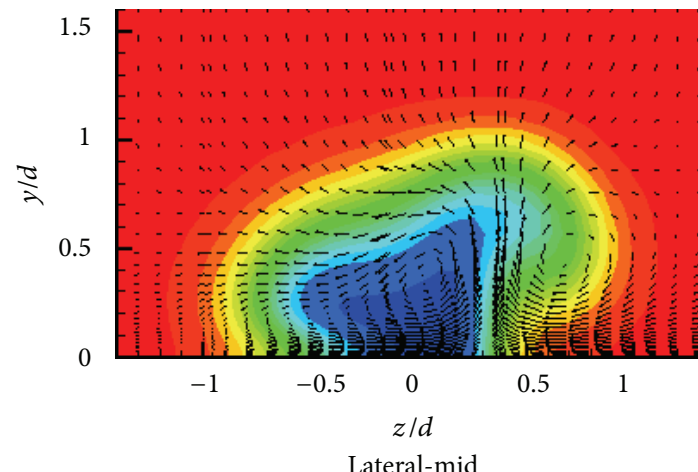

(d)

FIGURE 10: Effects of blockage on flow fields at normal plane of $x / d=1$ with blocking ratio of $0.5(M=0.5)$.

of kidney vortices, as seen in Figure 10(a). For the blockage located at trailing-exit, the bigger blocking ratio results in stronger normal coolant-jet penetration and larger scale of kidney vortices, as seen in Figure 10(b). When the blockage is located at lateral-exit, a pair of counter rotating vortices is distorted and the scale of vortices is enlarged more obviously for bigger blocking ratio, as seen in Figure 10(c). As regards to the blockage deposition at lateral-middle, it seems that the blockage deposition has less influence on the coolantjet penetration in relation to the lateral-exit blockage case, as seen in Figure 10(d).

Figure 11 presents the effects of blocking ratio on laterally averaged adiabatic film cooling effectiveness under blowing ratio of 0.5 when the blockage is deposited in the vicinity of coolant-hole exit. From this figure, it is viewed that the blocking ratio has important influence on the film cooling characteristics. For the leading-exit blockage, the film cooling effectiveness is enhanced as the blocking ratio increases. It is indicated that the larger blockage deposited at this position is benefit to transfer more coolant-jet momentum to streamwise direction. When the blockage is deposited at trailing-exit or lateral-exit, the film cooling effectiveness is generally decreased as the blocking ratio increases.

3.3. Effects of Blowing Ratio. Figure 12 presents the effects of blowing ratio on laterally averaged adiabatic film cooling effectiveness under blocking ratio of 0.3. In the case of perfect hole, as seen in Figure 12(a), the higher cooling effectiveness is achieved under relative lower blowing ratio. The laterally averaged film cooling effectiveness is weaker under higher blowing ratio near the downstream of film-hole, owing to the coolant-jet lift off the surface. But in the far downstream of film-hole, the film cooling is enhanced under higher blowing ratio due to its reattachment and stronger streamwise flow momentum. When the partial blockage is deposited at leading-exit, as seen in Figure 12(b), the laterally averaged film cooling effectiveness beyond $x / d>5$ is enhanced significantly, and the film cooling effectiveness is increased with the blowing ratio. When the blockage is deposited at trailing-exit or lateral-exit, as seen in Figures $12(\mathrm{c})$ and $12(\mathrm{~d})$, the film cooling effectiveness is generally decreased as the blowing ratio increases, especially beyond blowing ratio of 1.0. As regards to the blockage depositions in the vicinity of the film-hole inlet, it seems that the partial blockage with blocking ratio of 0.3 has weak influences on the film cooling effectiveness under blowing ratio of 0.5 , as seen in Figures 12(e)-12(g). However it must be noticed that this result is concluded on the assumption of same blowing ratio. Under higher blowing ratio, it is found the blockage deposited at trailing- or lateral-edge in the vicinity of coolanthole inlet region may result in an obvious decrease of film cooling effectiveness. This is due to the distorted coolant flow inside coolant-hole by the blockage is difficult to be smooth under high blowing ratio. 


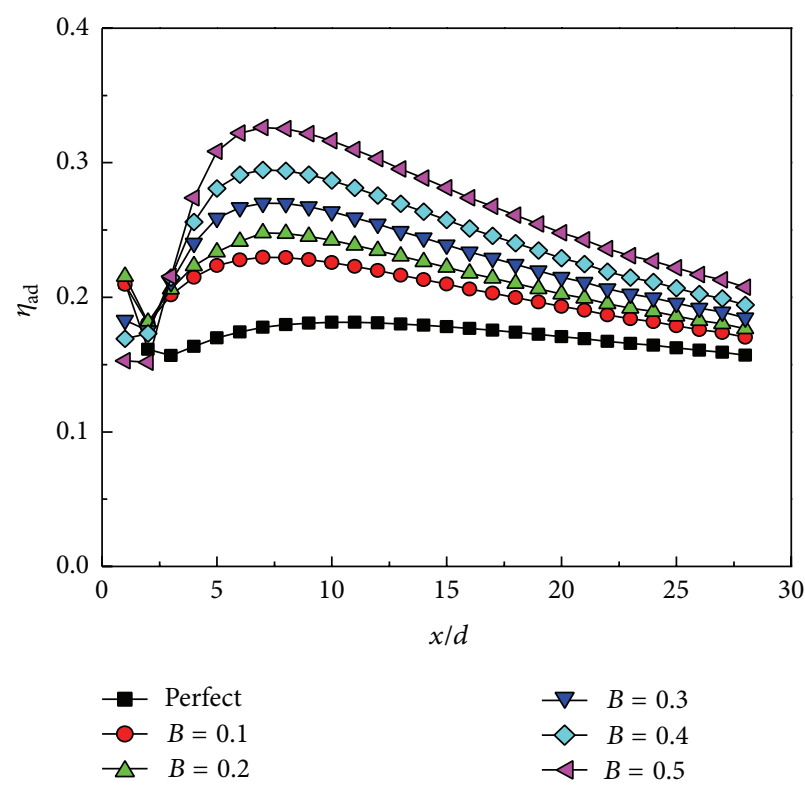

(a) Leading-exit

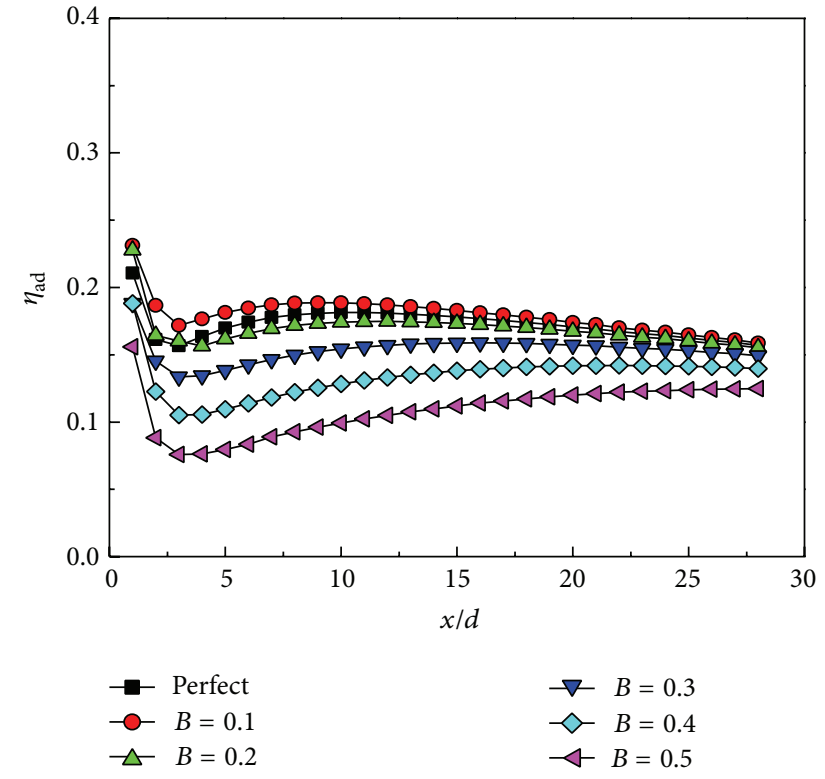

(b) Trailing-exit

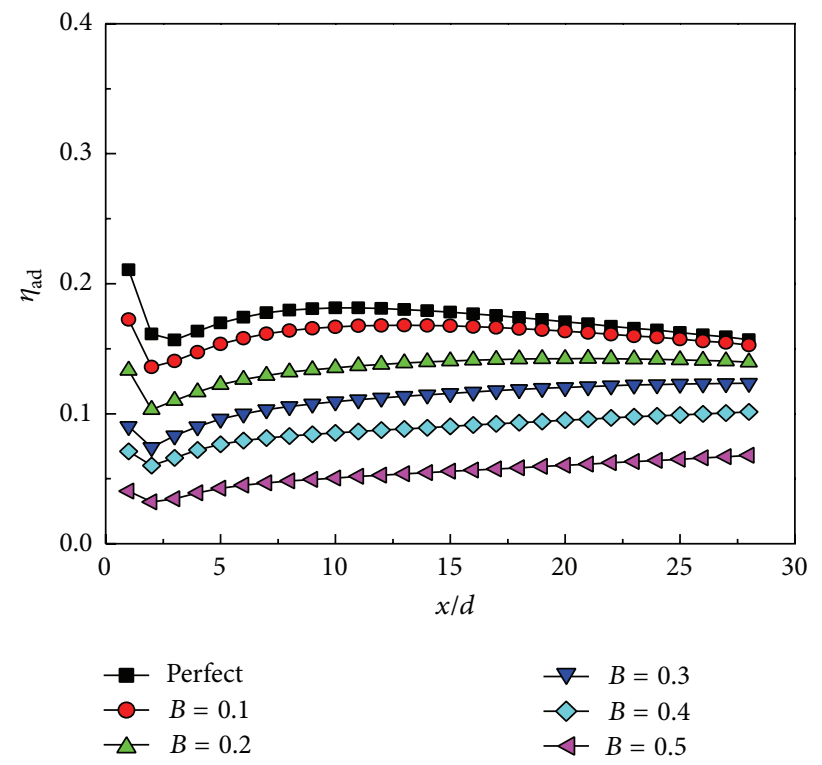

(c) Lateral-exit

FIGURE 11: Effect of blocking ratio on laterally averaged adiabatic effectiveness $(M=0.5)$.

\section{Conclusions}

Three-dimensional numerical calculation is performed to investigate the effects of partial blockage inside film holes on the film cooling effectiveness over a flat plate. Five blockage ratios ranged from 0.1 to 0.5 and a series of blockage positions are considered under the blowing ratios of $0.3-1.5$. The results are summarized as follows:

(1) The partial blockage located at the leading edge of coolant-hole exit mitigates the primary vortices due to mainstream-coolant jet interaction. The coolant jet penetration along vertical direction is suppressed and the peak velocity along streamwise direction is augmented under the action of partial blockage at the upstream side of film holes, providing an increase of film cooling effectiveness, especially under high blowing ratio.

(2) The partial blockages located at the trailing or lateral edges of coolant-hole exit weaken generally the film cooling effectiveness. The film cooling effectiveness is generally decreased as the blowing ratio increases, especially beyond blowing ratio of 1.0 .

(3) In relation to the partial blockage located in the vicinity of coolant-hole exit, the partial blockage 


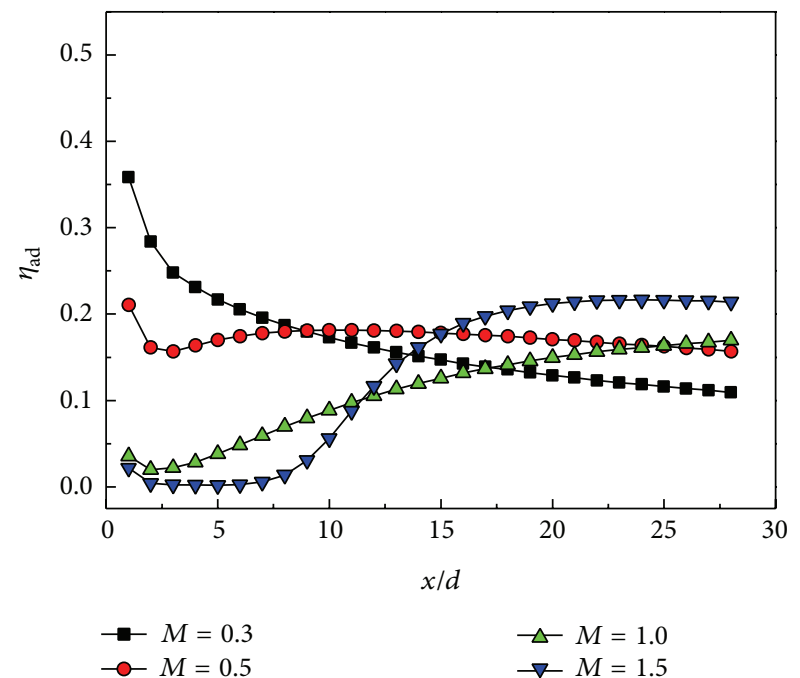

(a) Perfect

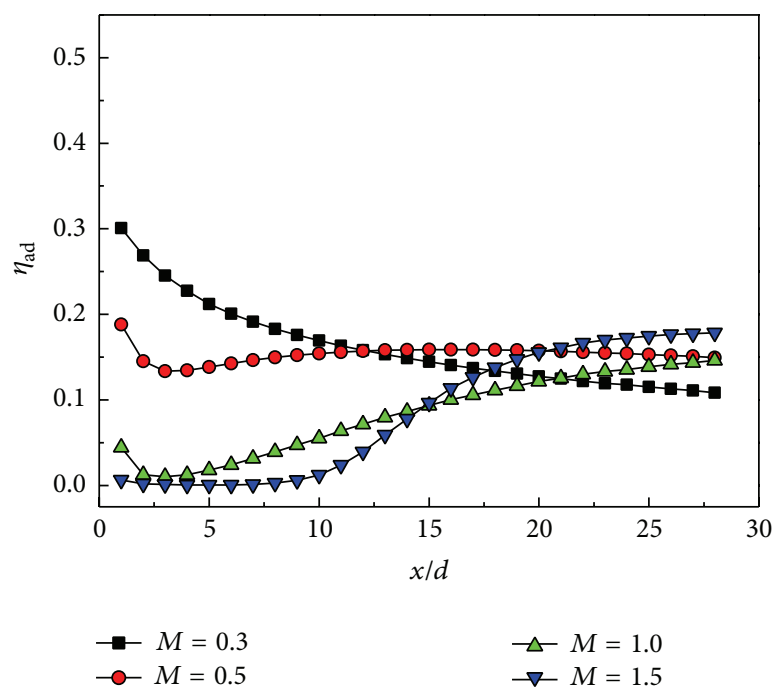

(c) Trailing-exit

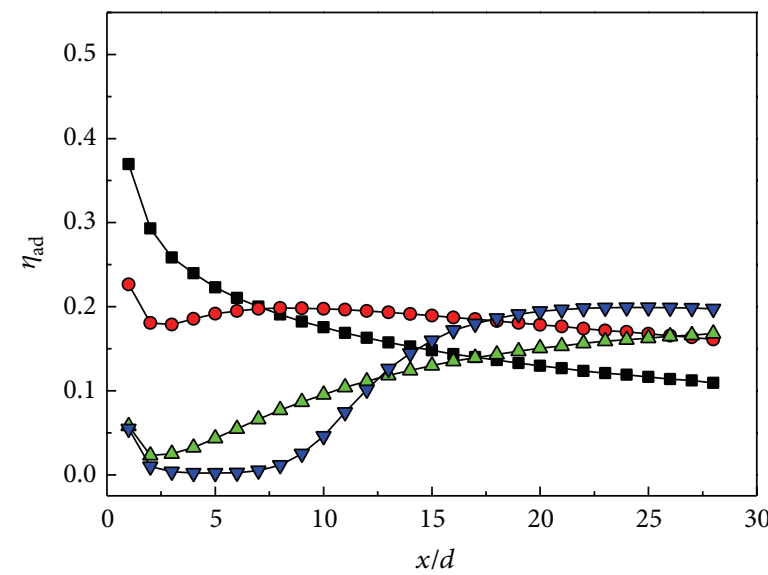

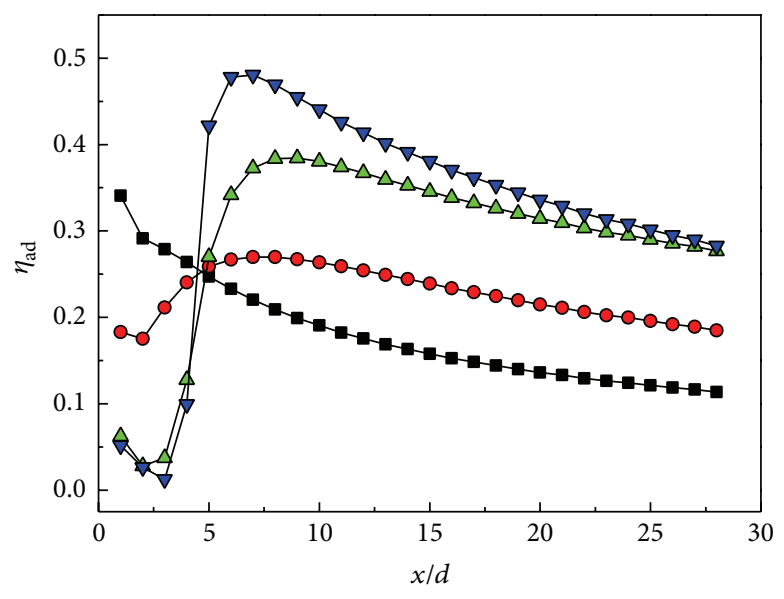

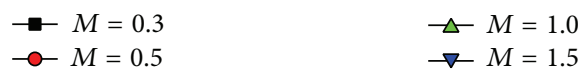

(b) Leading-exit

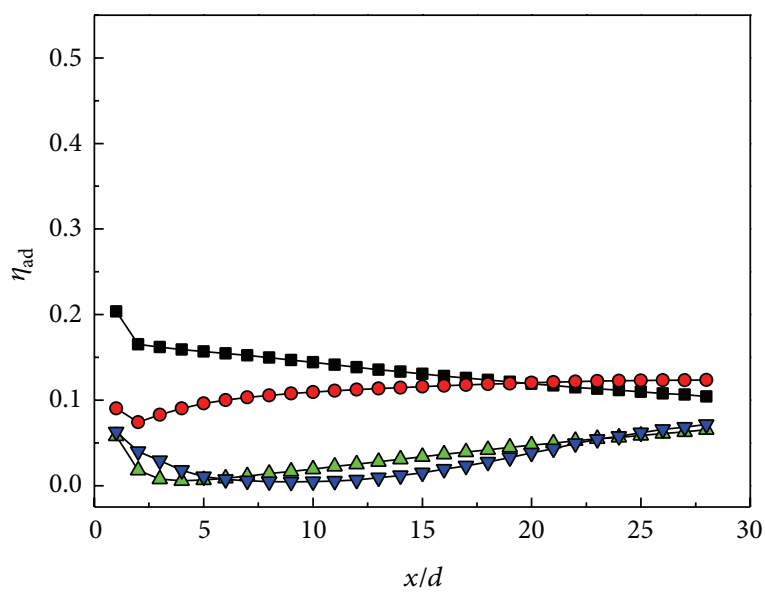

$\rightarrow-M=0.3$

$\triangle M=1.0$

$\multimap-M=0.5$

$\neg M=1.5$

(d) Lateral-exit

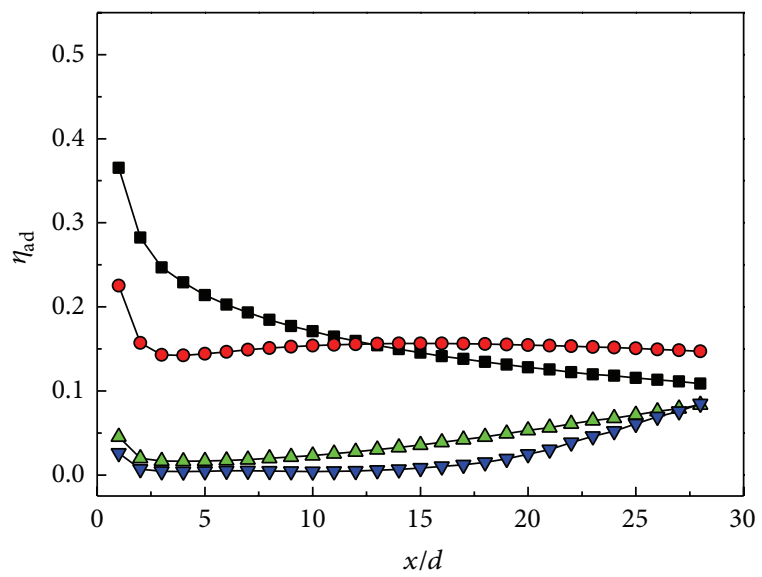

- $M=0.3$

$\multimap-M=0.5$

$\triangle M=1.0$

$\rightarrow M=1.5$

(f) Trailing-inlet

(e) Leading-inlet

$\triangle M=1.0$
$\rightarrow-M=1.5$

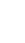




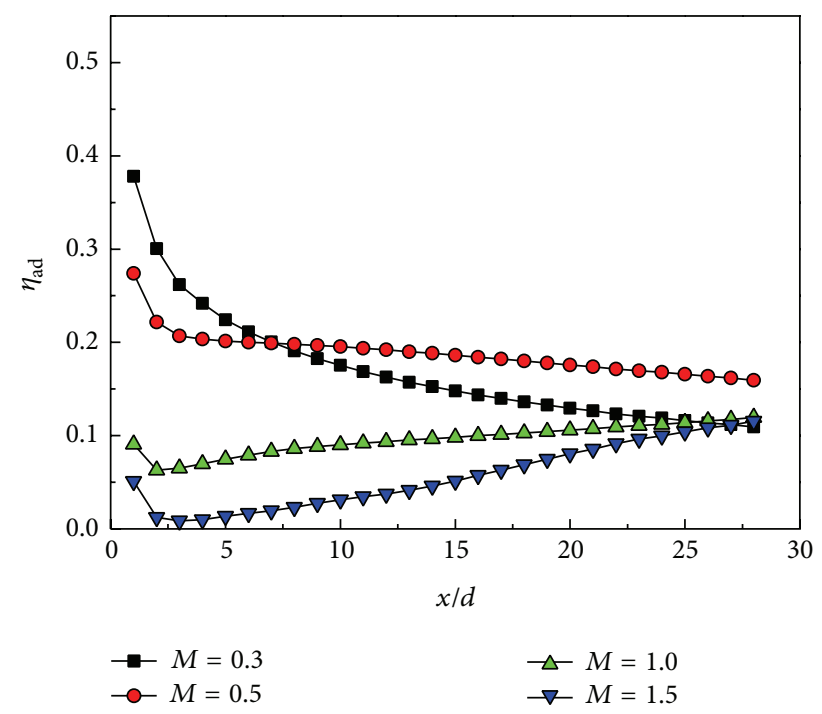

(g) Lateral-inlet

FIGURE 12: Effect of blowing ratio on laterally averaged adiabatic effectiveness $(B=0.3)$.

located in the vicinity of coolant-hole inlet or middle has less impaction on the film cooling effectiveness under low blowing ratio.

\section{Conflict of Interests}

The authors declare that there is no conflict of interests regarding the publication of this paper.

\section{Acknowledgment}

The authors gratefully acknowledge the financial support for this project from the National Natural Science Foundation of China (Grant no. 51276090).

\section{References}

[1] N. Sundaram and K. A. Thole, "Effects of surface deposition, hole blockage, and thermal barrier coating spallation on vane endwall film cooling," Journal of Turbomachinery, vol. 129, no. 3, pp. 599-607, 2007.

[2] J. Kim, M. G. Dunn, A. J. Baran, D. P. Wade, and E. L. Tremba, "Deposition of volcanic materials in the hot sections of two gas turbine engines," Journal of Engineering for Gas Turbines and Power, vol. 115, no. 3, pp. 641-651, 1993.

[3] M. B. Jovanovic, H. C. de Lange, and A. A. van Steenhoven, "Influence of laser drilling imperfection on film cooling performances," ASME Paper GT2005-68251, 2005.

[4] K. Thole, M. Gritsch, A. Schulz, and S. Wittig, "Flowfield measurements for film-cooling holes with expanded exits," Journal of Turbomachinery, vol. 120, no. 2, pp. 327-336, 1998.

[5] S. V. Ekkad, D. Zapata, and J. C. Han, "Film effectiveness over a flat surface with air and $\mathrm{CO}_{2}$ injection through compound angle holes using a transient liquid crystal image method," Journal of Turbomachinery, vol. 119, no. 3, pp. 587-593, 1997.
[6] H. Nasir, S. Acharya, and S. Ekkad, "Improved film cooling from cylindrical angled holes with triangular tabs: effect of tab orientations," International Journal of Heat and Fluid Flow, vol. 24, no. 5, pp. 657-668, 2003.

[7] M. Gritsch, W. Colban, H. Schär, and K. Döbbeling, "Effect of hole geometry on the thermal performance of fan-shaped film cooling holes," Journal of Turbomachinery, vol. 127, no. 4, pp. 718-725, 2005.

[8] R. S. Bunker, "A review of shaped hole turbine film-cooling technology," Journal of Heat Transfer, vol. 127, no. 4, pp. 441-453, 2005.

[9] Y. Yao and J. Zhang, "Investigation on film cooling characteristics from a row of converging slot-holes on flat plate," Science China Technological Sciences, vol. 54, no. 7, pp. 1793-1800, 2011.

[10] Y. Yao, J. Zhang, and L. Wang, "Film cooling on a gas turbine blade suction side with converging slot-hole," International Journal of Thermal Sciences, vol. 65, pp. 267-279, 2013.

[11] Y. Yao, J. Z. Zhang, and X. M. Tan, "Numerical study on film cooling from converging slot-hole on a gas turbine blade suction side," International Communications in Heat and Mass Transfer, vol. 52, pp. 61-72, 2014.

[12] R. S. Bunker, "Effect of partial coating blockage on film cooling effectiveness," ASME Paper 2000-GT-0244, 2000.

[13] M. B. Jovanović, H. C. de Lange, and A. A. van Steenhoven, "Influence of hole imperfection on jet cross flow interaction," International Journal of Heat and Fluid Flow, vol. 27, no. 1, pp. 42-53, 2006.

[14] M. B. Jovanović, H. C. de Lange, and A. A. van Steenhoven, "Effect of hole imperfection on adiabatic film cooling effectiveness," International Journal of Heat and Fluid Flow, vol. 29, no. 2, pp. 377-386, 2008.

[15] P. Demling and D. G. Bogard, "The effects of obstructions on film cooling effectiveness on the suction side of a gas turbine vane," ASME Paper GT2006-90577, 2006.

[16] W. S. Walsh, K. A. Thole, and C. Joe, "Effects of sand ingestion on the blockage of film-cooling holes," ASME Paper GT 200690067, 2006. 
[17] N. D. Cardwell, K. A. Thole, and S. W. Burd, "Investigation of sand blocking within impingement and film-cooling holes," Journal of Turbomachinery, vol. 132, no. 2, Article ID 021020, 2010.

[18] D. K. Walters and J. H. Leylek, "Impact of film-cooling jets on turbine aerodynamic losses," Journal of Turbomachinery, vol. 122, no. 3, pp. 537-545, 2000.

[19] M. Silieti, A. J. Kassab, and E. Divo, "Film cooling effectiveness: comparison of adiabatic and conjugate heat transfer CFD models," International Journal of Thermal Sciences, vol. 48, no. 12, pp. 2237-2248, 2009.

[20] M. J. Ely and B. A. Jubran, "A numerical evaluation on the effect of sister holes on film cooling effectiveness and the surrounding flow field," Heat and Mass Transfer, vol. 45, no. 11, pp. 1435-1446, 2009.

[21] K. Harrison and D. Bogard, "Comparison of RANS turbulence models for prediction of film cooling performance," ASME Paper GT2008-50366, 2008.

[22] C. Yang and J. Zhang, "Experimental investigation on film cooling characteristics from a row of holes with ridge-shaped tabs," Experimental Thermal and Fluid Science, vol. 37, pp. 113120, 2012. 


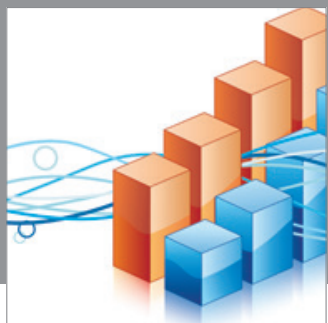

Advances in

Operations Research

mansans

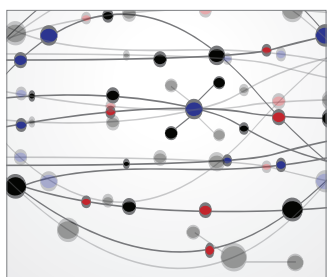

The Scientific World Journal
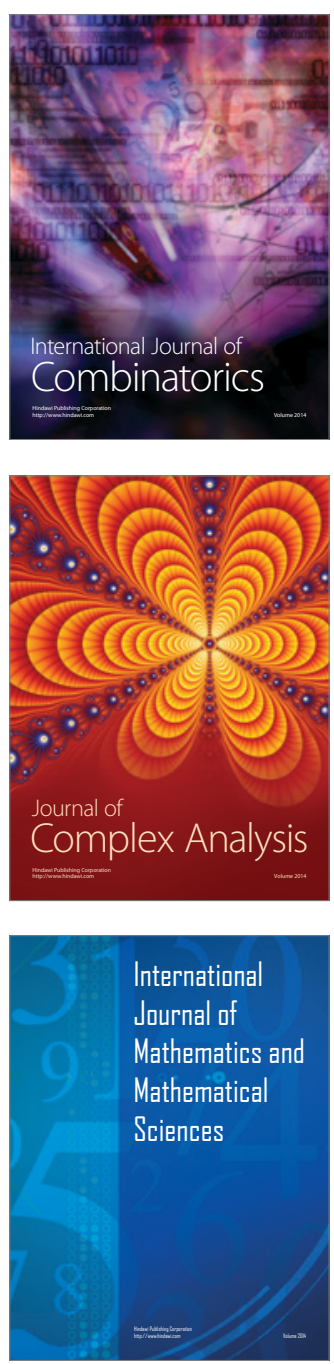
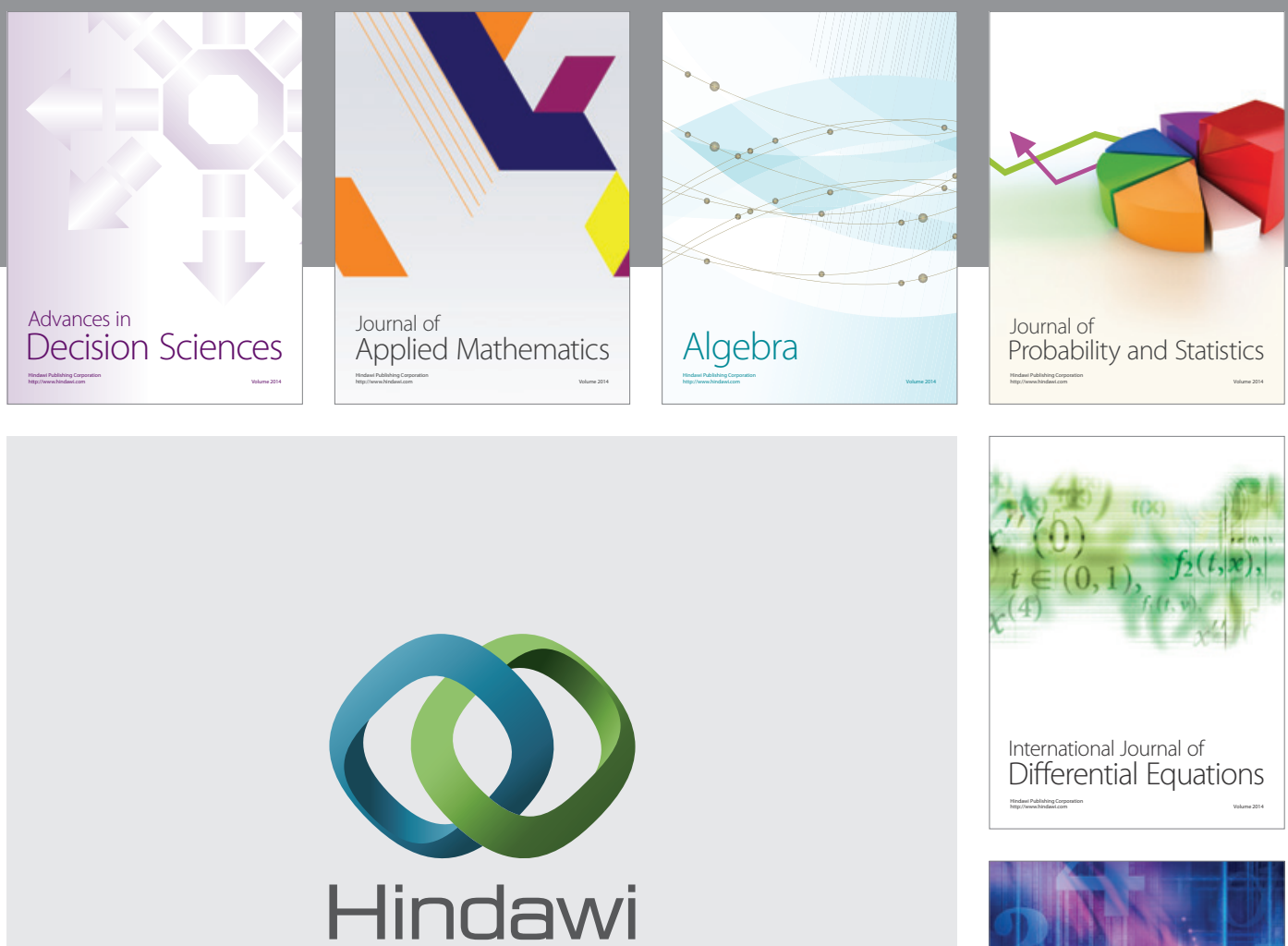

Submit your manuscripts at http://www.hindawi.com
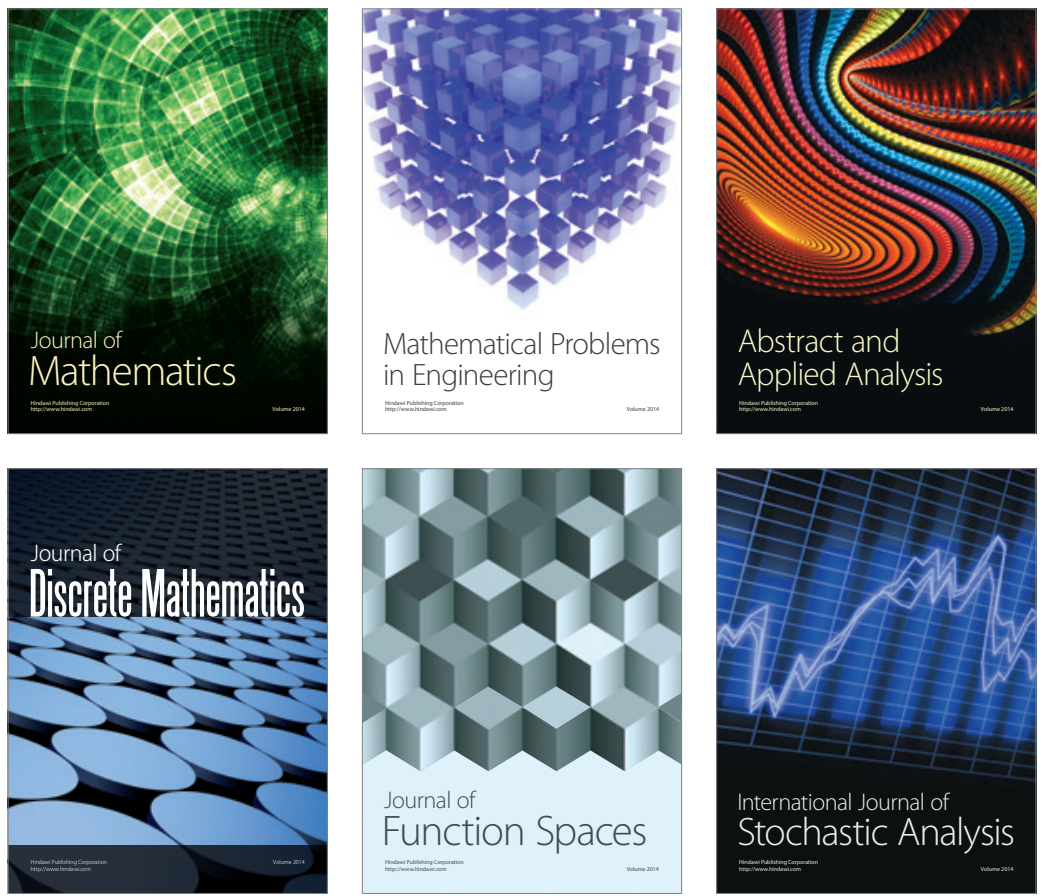

Journal of

Function Spaces

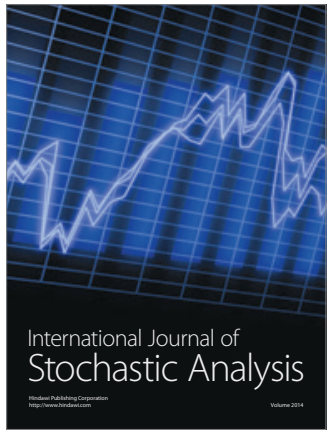

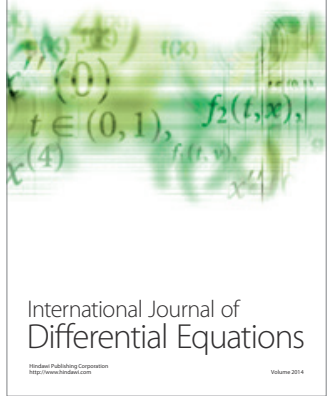
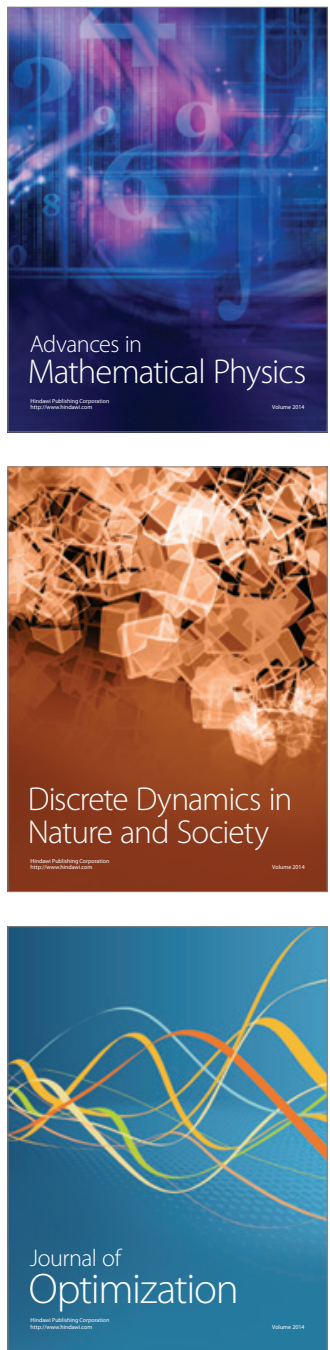